\title{
Effect of the harvest procedure and tissue site on the osteogenic function of and gene expression in human mesenchymal stem cells
}

\author{
DIRK HENRICH $^{1 *}$, CHRISTOPH NAU $^{1 *}$, SASKIA BO KRAFT $^{1}$, MAXIMILIAN ZOLLFRANK $^{1}$, \\ KERSTIN KONTRADOWITZ ${ }^{1}$, ELSIE OPPERMANN ${ }^{2}$, JUDITH SCHULTHEISS ${ }^{1}$, \\ SIMON MEIER ${ }^{1}$, JOHANNES FRANK ${ }^{1}$, INGO MARZI ${ }^{1}$ and CAROLINE SEEBACH ${ }^{1}$ \\ Departments of ${ }^{1}$ Trauma, Hand and Reconstructive Surgery, and ${ }^{2}$ Visceral and Abdominal Surgery, \\ Goethe University Hospital, 60590 Frankfurt am Main, Germany
}

Received July 15, 2015; Accepted January 29, 2016

DOI: $10.3892 /$ ijmm.2016.2489

\begin{abstract}
Evidence has indicated that mesenchymal stem cells (MSCs) harvested with the Reamer/Irrigator/ Aspirator (RIA) procedure exhibited an improved osteogenic differentiation capability compared with MSCs obtained by bone marrow aspiration from the iliac crest. In the present study, we hypothesized that the harvest procedure indeed influences the osteogenic activity of human MSCs more than the tissue site itself. Concentration [by colony forming unit-fibroblast (CFU-F) assay], calcification (by von Kossa staining), collagen deposition, gene expression and the gene methylation of the bone morphogenetic protein (BMP)-2 pathway [BMP2, SMAD5 and runt-related transcription factor 2 (RUNX2)], the Wnt pathway [WNT3, dickkopf-1 (DKK1), low-density lipoprotein receptor-related protein 5 (LRP5) and $\beta$-catenin] and osteogenic genes [alkaline phosphatase (ALP), collagen, type I, alpha 1 (COL1A) and osteocalcin] were analyzed in the MSCs isolated intraoperatively from the iliac crest with a spoon $(n=14)$, from the femur with a spoon $(n=7)$, from the femur with the RIA procedure $(n=13)$ and from the iliac crest by fine-needle aspiration ( $n=8$, controls). A Bonferroni-Holm corrected $\mathrm{p}$-value $<0.05$ indicated a statistically significant difference. The concentration of CFU-F in the MSCs was increased in the RIA debris in comparison with that in the iliac crest aspirates (trend) and the femur (spoon, significant). Calcium deposition was highest in the femur-derived MSCs (by RIA) and was significantly increased in comparison with that in the iliac crest-derived MSCs (spoon, aspirate). The gene expression of BMP2, SMAD5, RUNX2, osteocalcin, and COL1A was significantly increased in the femur-derived MSCs (spoon) and the iliac crest aspirate derived-MSCs in comparison with that
\end{abstract}

Correspondence to: Professor Dirk Henrich, Department of Trauma, Hand and Reconstructive Surgery, Goethe University Hospital, Theodor-Stern-Kai 7, 60590 Frankfurt am Main, Germany

E-mail: d.henrich@trauma.uni-frankfurt.de

*Contributed equally

Key words: mesenchymal stem cells, Reamer/Irrigator/Aspirator, spongiosa, femur, iliac crest, gene expression, gene methylation in the femur-derived MSCs (by RIA). There was no significant diversity between the samples obtained using a spoon (from the femur or iliac crest). Calcium deposition and osteogenic gene expression decreased significantly with the increasing passage number in all the samples. The methylation of genes did not correlate with their respective gene expression and inconsistent differences were observed between the groups. Herein, we provide evidence that the harvest procedure is a critical factor in the osteogenesis of MSCs in vitro. The MSCs isolated from the femur and iliac crest using a spoon exhibit no significant differences. The altered gene expression and function of the femur-derived MSCs (by RIA) may be due to the harsh isolation procedure. The variable differentiation ability of the MSCs, which depends on the harvest site and the harvest technique, as well as the rapid loss of the osteogenic differentiation capacity with the increasing culture duration should be taken into consideration when using MSCs as a potential therapeutic application for bone tissue engineering.

\section{Introduction}

Extensive bone defects continue to pose a major challenge in orthopedic and trauma patients. Autologous and allogenous bone grafts obtained from the iliac crest and fibula are considered to be the gold standard for treating these defects. However, in cases of multi-fragmentary fractures, pseudarthrosis, peri-prosthetic fractures, infection and tumor resection, the resulting defects are large and the volumes of bone available for grafting are insufficient. Furthermore, bone harvesting is often accompanied by complications, such as donor site pain, limited bone availability and extended operative times (1). The combination of mesenchymal stem cells (MSCs) with an appropriate biomaterial scaffold has led to the extensive regeneration of bone tissue (2-4). These findings suggest the possibility of engineering large volumes of bone tissue.

MSCs are easily isolated from the iliac crest by fine needle puncture, whereas MSCs located in the marrow of the femur are only accessible during a surgical intervention, such as intramedullary nailing that is the treatment of choice for the stabilization of fractures of long tubular bones. The application of the novel technique, Reamer/Irrigator/Aspirator (RIA), allows the harvest of vital bone marrow from the femur by continuous irrigation 
and simultaneous aspiration of the irrigation fluid. The irrigation fluid, as well as the osseous particles within the irrigation fluid are harvested using a filter. It has been demonstrated that the reaming debris obtained using the RIA technique contains elevated levels of fibroblast growth factor (FGF)-1, platelet-derived growth factor (PDGF), insulin-like growth factor (IGF)-1, transforming- growth factor (TGF)- $\beta 1$ and bone morphogenetic protein (BMP)-1 in comparison with samples obtained from the iliac crest using the needle puncture/aspiration technique (5). Moreover, it was also demonstrated that human reaming debris is a rich source of multipotent stem cells. The yielded cells exhibit a phenotype and a plasticity commonly attributed to MSCs in culture (6). However, little is known about the quantitative and qualitative properties of isolated stem cells. In our previous study, we found that the MSCs harvested using the RIA technique demonstrated sustained and higher osteogenic properties than the MSCs harvested from the iliac crest using the traditional aspiration technique (7).

Thus, it can be hypothesized that the mechanical stress of the RIA procedure may cause cellular activation, leading to an altered differentiation response. Moreover, the high daily mechanical environment load of the femur may contribute to the alteration of the methylation pattern of genes that induces the osteogenic differentiation of the MSCs compared with the iliac crest. The DNA methylation pattern is inherited by daughter cells (8); this may explain why femur-derived MSCs are capable of sustaining osteogenic capabilities in comparison with MSCs derived from other tissue sites.

In order to determine the effects of the harvest procedure, we compared MSCs isolated from the femur harvested using hte RIA technique with MSCs isolated from the femur harvested by gentle scraping with a spoon. To determine the influence of the tissue site, we compared femur-derived MSCs with iliac crest bone-derived MSCs, both harvested by gentle scraping using a spoon. We analyzed osteogenic differentiation by means of von Kossa staining and by determination of the expression of genes involved in the osteogenic differentiation of MSCs (BMP-2 signaling, WNT-3 pathway and osteogenic marker genes). Moreover, we examined whether the tissue site-specific gene methylation pattern of MSC is associated with a specific harvest site as regards osteogenic differentiation potential and whether putative differences in osteogenic differentiation between the MSC samples were maintained over multiple passaging.

\section{Subjects and methods}

Ethics. The sampling of bone marrow from the various tissue sites using either a spoon or the RIA technique was approved and performed in accordance with the regulations set forth by the Ethics Committee Goethe University Hospital (Frankfurt am Main, Germany; project no. 94/10, samples from patients; project no. 329/10, anonymized samples from healthy donors), and in accordance with German law. Written informed consent was obtained from all patients and healthy donors prior to obtaining the samples.

Group sizes and demographic characteristics of the study participants. A total of 13 bone marrow samples were obtained from the femur (by RIA, from 7 males and 6 females), 7 samples were obtained from the femur (using a spoon, from
5 males and 2 females), 14 samples were obtained from the iliac crest (using a spoon, from 7 males and 7 females) and 8 samples were obtained from the iliac crest (by fine-needle aspiration) were analyzed. The mean age of the patients did not differ significantly between the groups [age is presented as median and interquartiles (25\% quartile / $75 \%$ quartile)]: RIA [51 (42/54)], femur [48 (31/69)], iliac crest [51 (36/63)]. The gender distribution was also comparable between the groups and did not differ significantly. The age and gender of the iliac crest (aspirate) donors were unavailable.

Isolation of MSCs obtained from different sources. MSCs from the iliac crest were isolated as previously described (9). Briefly, bone marrow aspirates were washed once using phosphatebuffered saline (PBS). The pellet was resuspended in PBS and layered on a Ficoll density gradient $(\mathrm{d}=1,077 \mathrm{~g} / \mathrm{ml}$, Biochrom, Berlin, Germany). Following centrifugation (30 min, 1,100 x g), the mononuclear cells in the interphase were collected and washed twice using PBS (10 min, $900 \mathrm{x} \mathrm{g}$ ) containing $2 \%$ fetal bovine serum (FBS). The cells were resuspended in $3 \mathrm{ml}$ MesenCult + Supplements (Cell Systems, St. Katharinen, Germany) and were counted.

The cell suspension was then divided. One million mononuclear cells were used for the colony forming unit-fibroblast (CFU-F) assay and the remaining cells were cultured in order to obtain MSCs for further analysis (osteogenic differentiation, gene expression of osteogenic marker genes and methylation analysis). The mononuclear cells were cultured in MesenCult + Supplements at $37^{\circ} \mathrm{C}$ in $5 \% \mathrm{CO}_{2}$. The medium was changed 3 times each week.

Femoral reaming debris, particularly the spongy bone from the iliac crest or the femur, was placed in a sterile Petri dish. Spongy bone was cut into small sections $(2-3 \mathrm{~mm})$ using a sterile scalpel. The bone marrow was flushed out from the bony fragments several times with PBS and the collected cells were pelleted once.

The pellet was resuspended in PBS and filtered through 100-, 70- and 40- $\mu \mathrm{m}$ mesh (BD Biosciences, Heidelberg, Germany). Subsequently, the cell suspension was layered on a Ficoll density gradient. Further processing was performed as described for the isolation of pelvic MSCs obtained by fineneedle aspiration.

Spongious bone from the iliac crest was carefully obtained using a spoon during the bone harvest procedure for autologous bone transplantation. Spongious bone from the femur was carefully obtained using a spoon during the surgical treatment of femur fractures from the defect site. The isolation of MSCs from the spongious bone for was carried out analogously as described for MSCs harvested from femoral reaming debris.

When the cells reached $80 \%$ confluency, the MSCs were subdivided in a 1:1 ratio. The cells were rinsed with PBS and subsequently incubated with Accutase (PAA-Laboratories, Linz, Austria) for $10 \mathrm{~min}$. The detached MSCs were washed twice in MesenCult medium and further subcultivated. For the experiments, the cells from the 1st, 3rd and 6th culture passages were used. A period of approximately 2-3 weeks was required to obtain a sufficient number of MSCs to begin the experiments (passage no. 1) and at least 3 further weeks for cells of passage no. 3 , and a further 6 weeks, respectively for cells of passage no. 6 . 
$C F U-F$ assay and osteogenic differentiation. The concentration of the MSCs was assessed by CFU-F assay. Mononuclear cells were seeded at a density of $1 \times 10^{6}$ cells per $25 \mathrm{~cm}^{2}$ culture flask and cultivated for 14 days in MesenCult medium + Supplements at $37^{\circ} \mathrm{C}$ in $5 \% \mathrm{CO}_{2}$ and $100 \%$ humidity. The medium was changed thrice a week. The colonies were stained using DiffQuick (Medion Diagnostics, Düdingen, Switzerland) and digitized using an image analysis system (BioRad, Munich, Germany). The colonies were subsequently counted.

Osteogenic differentiation was induced as previously described (9). Briefly, the cells were seeded at a density of $3 \times 10^{3} / \mathrm{cm}^{2}$ in MesenCult $+10 \%$ fetal calf serum (FCS) containing dexamethasone $\left(1 \times 10^{-7} \mathrm{M}\right)$, ascorbic acid-2-phosphate $\left(5 \times 10^{-5} \mathrm{M}\right)$ and $\beta$-glycerophosphate $\left(1 \times 10^{-2} \mathrm{M}\right)$. All substances were obtained from Sigma-Aldrich (Munich, Germany). The medium was changed thrice a week. After 14 days, the extent of calcium deposition was assessed by von Kossa staining. At least 5 random microscopic fields were selected at a magnification of x 50 for analysis. Subsequently, the area of stained calcium deposits was determined using Cell Explorer software (BioSciTec, Frankfurt, Germany).

Gene expression analysis by reverse transcription-quantitative polymerase chain reaction ( $R T-q P C R)$. Total RNA was isolated from the MSCs using the RNeasy system (Qiagen, Hilden, Germany) according to the manufacturer's instructions. The quality and the amount of RNA were determined using a NanoDrop ND-1000 device (NanoDrop Technologies, Wilmington, DE, USA). Contaminating genomic DNA was removed by digestion with the RNase-free DNase-Kit according to the manufacturer's instructions (Qiagen).

Each 250 ng of RNA was reverse transcribed using the Affinity script QPCR-cDNA synthesis kit (Stratagene, La Jolla, CA, USA) according to the manufacturer's instructions. Subsequently, SYBR-Green-based quantitative (real-time) (qPCR) was performed on a Stratagene Mx3005P qPCR system (Stratagene).PCR wasperformedusingtarget-specific primersfor alkaline phosphatase, liver/bone/kidney (ALPL, NM_000478; catalog number, PAHS-026), catenin beta 1 (CTNNB1, NM_001904; catalog number, PPH00643F), BMP-2 (NM_00120; catalog number, PPH00549C), collagen, type I, alpha 1 (COL1A, NM_000088; catalog number, PPH01299F), dickkopf-1 (DKK1,NM_012242; catalog number,PPH01752C), low-density lipoprotein receptor-related protein 5 (LRP5, NM_002335; catalog number, PPH02315F), osteocalcin [also known as bone gamma-carboxyglutamate protein (BGLAP), NM 199173; catalog number, PPH01898A], runt-related transcription factor 2 (RUNX2, NM_004348; catalog number, PPH01897C), SMAD-5 (NM_005903; catalog number, PPH01940C) and Wnt-3a (WNT3A, NM_033131; catalog number, PPH02772B) (all purchased from Qiagen). The expression of glyceraldehyde-3-phosphate dehydrogenase (GAPDH, NM_002046.3, catalog number, PPH00150E) was measured as a reference gene. The PCR cycling conditions were as follows: initial denaturation at $95^{\circ} \mathrm{C}$ for $10 \mathrm{~min}$, followed by 40 cycles at $95^{\circ} \mathrm{C}$ for $15 \mathrm{sec}$ and finally a melting curve at $60^{\circ} \mathrm{C}$ for $1 \mathrm{~min}$. The relative quantification of the mRNA levels of the target genes was determined using the comparative (CT; threshold

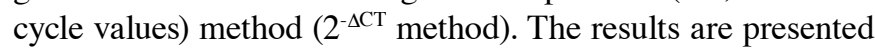
as the fold change relative to GAPDH gene expression.
Gene methylation analysis. Total DNA was extracted from $5 \times 10^{5}$ MSCs using the QIAampDNA Minikit(Qiagen) according to the manufacturer's instructions. The DNA concentration and purity were measured using a NanoDrop device (NanoDrop Instruments/Thermo Scientific, Schwerte, Germany). EpiTect Methyl qPCR assays (Qiagen) were perfomed to determine the methylation status of ALP (ALPL), catenin beta 1 (CTNNB1), BMP-2 (BMP2), collagen-1a (COL1A), dickkopf-1 (DKK1), LRP5 (LRP5), osteocalcin (BGLAP), runx-2 (RUNX2), smad-5 (SMAD5) and Wnt3a (WNT3A). The assay procedures were performed according to the manufacturer's instructions. Briefly, DNA $(250 \mathrm{ng} / \mu \mathrm{l})$ was distributed to 4 reaction tubes containing either methylation-sensitive restriction enzymes, methylation-resistant enzymes, or a mixture of both methylation-sensitive and methylation-resistant enzymes and incubated at $37^{\circ} \mathrm{C}$ overnight in a heating block. Following the heat inactivation of the enzymes $\left(65^{\circ} \mathrm{C}, 20 \mathrm{~min}\right)$, the remaining DNA was amplified using SYBR-Green-based primer assays for the detection of the above-mentioned genes. The $\mathrm{Ct}$ values of each digest were compared with mock digest and the relative amounts of hypermethylated, intermediate methylated and unmethylated DNA were calculated using an Excel sheet provided by the manufacturer (Qiagen).

Statistical analysis. The Kruskal-Wallis test followed by Bonferroni-Holm correction for multiplicity were used for group comparisons and comparisons between the different culture passages. A Bonferroni-adjusted Fisher's Exact test was used to calculate significance in gender distribution between the groups. The Spearman-Rank correlation was applied for correlational analysis. A p-value $<0.05$ was considered to indicate a statistically significant difference.

\section{Results}

Cell numbers and MSC concentrations. The median number of mononuclear cells per $\mathrm{ml}$ sample differed significantly between the cells obtained from the femoral reaming debris $\left(6.8 \times 10^{6}\right.$ cells), iliac crest spongiosa $\left(3.3 \times 10^{6}\right.$ cells $)$ and iliac crest aspirates $\left(1.4 \times 10^{6}\right.$ cells $)$ compared to the cells obtained from the femur spongiosa using a spoon $\left(5.0 \times 10^{5}\right.$ cells).

The concentration of MSCs per $1.0 \times 10^{6}$ mononuclear cells was measured by CFU-F assay. We observed a higher CFU-F number in the cells obtained from the femoral reaming debris (63.5), iliac crest aspirate (39.0) and spongy iliac crest bone (30.0) in comparison with those from the spongy bone from the femur $(9.0, \mathrm{p}<0.05)$. Furthermore, the CFU-F-number in the cells obtained from the femoral reaming debris was higher than that in the cells from the spongy bone from the iliac crest and the iliac crest aspirates (trend, p<0.09) (Fig. 1A).

Osteogenic differentiation is dependent on the tissue site and isolation procedure. The MSCs of the first culture passage were analyzed. The MSCs obtained using the RIA technique exhibited a higher calcium deposition in comparison with the MSCs isolated from the iliac crest (by fine-needle aspiration) and the MSCs obtained from the iliac crest (using a spoon) $(\mathrm{p}<0.05)$. No significant differences were observed between the MSCs derived from the femur (using a spoon), the iliac crest (using a spoon) and the iliac crest aspirates (Fig. 1B). Additionally, the 
A



B



Figure 1. (A) Increased mesenchymal stem cell (MSC) concentration and (B) increased calcium deposition in femor-derived MSCs harvested using the Reamer/Irrigator/Aspirator (RIA) technique. Median and quartiles are shown. MSC concentration was determined using the colony forming unit-fibroblast (CFU-F) assay. Calcium deposition was measured by the evaluation of von Kossa staining as a percentage of black staining as described in the Materials and methods. " $p<0.05$, statistically significant difference. MSCs obtained from the femur by RIA (F-RIA), from the femur using a spoon (F-Spo), from the iliac crest using a spoon (IC-Spo) and from the iliac crest by fine-needle aspiration (IC-Asp) were analyzed.

expression of the osteogenic marker genes, BGLAP, COL1A and ALPL, was analyzed. The overall expression of BGLAP and COL1A was highest in the MSCs obtained from the iliac crest aspirates both in the controls and following incubation with osteogenic differentiation medium. The gene expression in the MSCs isolated using a spoon from the iliac crest and the femur did not differ significantly. However, the gene expression in the MSCs obtained from the femur (using a spoon) was consistently higher in comparison with that in the MSCs obtained using the RIA technique. The gene expression of ALPL did not differ significantly between the groups. Osteogenic differentiation over a period of 14 days did not alter the gene expression levels significantly in comparison with those in the MSCs under control conditions (Fig. 2 and Table I).

Gene expression of BMP-2 and Wnt signaling components. One of the main objectives of the present observational study was to determine the expression of genes involved in osteogenic differentiation pathways, depending on the tissue site and the isolation procedure being applied. The highest expression of BMP2, SMAD5 and RUNX2 was observed in the iliac crest-derived MSCs (by fine-needle aspiration) and the lowest expression in the femur-derived MSCs (by RIA).
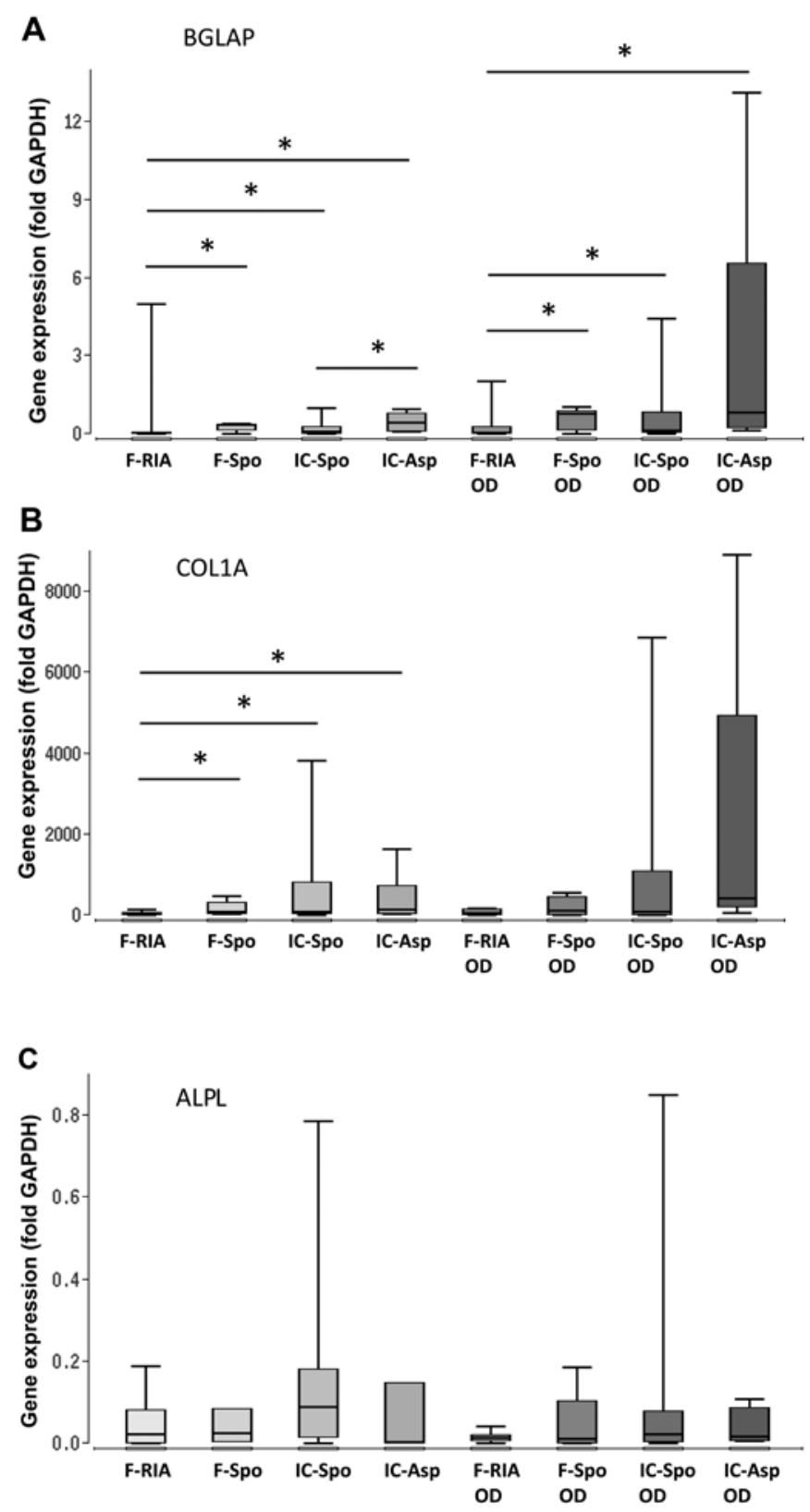

Figure 2. Expression of osteogenic marker genes depending on the tissue site and harvest procedure of mesenchymal stem cells (MSCs) under control and osteogenic-inducing conditions (OD). Gene expression of (A) BGLAP, (B) COL1A and (C) ALPL was normalized to GAPDH gene expression by the $\Delta \mathrm{Ct}$ method. Values are presented as boxplots of the median. MSCs obtained from the femur by RIA (F-RIA), from the femur using a spoon (F-Spo), from the iliac crest using a spoon (IC-Spo) and from the iliac crest by fine-needle aspiration (IC-Asp) were analyzed. * $\mathrm{p}<0.05$. Exact p-values are additionally shown in Table I. RIA, Reamer/Irrigator/Aspirator.

The differences in gene expression between both groups were statistically significant. Gene expression in the femurderived MSCs (using a spoon) was also significantly increased in comparison with that in the femur-derived MSCs (by RIA) (Fig. 3 and Table I).

Furthermore, we analyzed the gene expression of WNT3A, LRP5, DKK1 and CTNNB1, the key components of the canonical Wnt signaling pathway. Our results demonstrated a consistent and significantly higher expression of the iliac crest- 
Table I. Expression of genes involved in the osteogenic differentiation of mesenchymal stem cells (MSCs) cultured under (A) control (A) and (B) osteogenic-inducing conditions, as well as (C) intergroup comparisons according to the harvest site and harvest technique. ${ }^{a}$

A, Control conditions

\begin{tabular}{|c|c|c|c|c|}
\hline Gene & Femur (RIA) & Femur (spoon) & Iliac crest (spoon) & Iliac crest (aspirates) \\
\hline BMP2 & & & $\mathrm{p}=0.05$ vs. RIA & $\mathrm{p}=0.009 \mathrm{vs} . \mathrm{RIA}$ \\
\hline SMAD5 & & & & $\mathrm{p}=0.02$ vs. RIA \\
\hline RUNX2 & & & $\mathrm{p}=0.01 \mathrm{vs} . \mathrm{RIA}$ & $\mathrm{p}=0.004$ vs. RIA \\
\hline WNT3A & & & & $\mathrm{p}=0.04$ vs. RIA \\
\hline LRP5 & & & & $\begin{array}{l}\mathrm{p}=0.03 \text { vs. } \mathrm{RIA} \\
\mathrm{p}=0.05 \text { vs. iliac crest (spoon) }\end{array}$ \\
\hline DKK1 & & & & $\mathrm{p}=0.04$ vs. RIA \\
\hline CTNNB1 & & & & $\mathrm{p}=0.04$ vs. RIA \\
\hline BGLAP & & $\mathrm{p}=0.05$ vs. RIA & $\mathrm{p}=0.04$ vs. RIA & $\begin{array}{l}\mathrm{p}=0.006 \mathrm{vs} . \mathrm{RIA} \\
\mathrm{p}=0.02 \mathrm{vs} . \text { iliac crest (spoon) }\end{array}$ \\
\hline COL1A & & $\mathrm{p}=0.02$ vs. RIA & $\mathrm{p}=0.02$ vs. RIA & $\mathrm{p}=0.002$ vs. RIA \\
\hline ALPL & & & & \\
\hline
\end{tabular}

B, Osteogenic-inducing conditions

\begin{tabular}{|c|c|c|c|c|}
\hline Gene & Femur (RIA) & Femur (spoon) & Iliac crest (spoon) & Iliac crest (aspirates) \\
\hline BMP2 & & $\mathrm{p}=0.03$ vs. RIA & $\mathrm{p}=0.004 \mathrm{vs} . \mathrm{RIA}$ & $\mathrm{p}=0.001 \mathrm{vs} . \mathrm{RIA}$ \\
\hline SMAD5 & & $\mathrm{p}=0.05 \mathrm{vs} . \mathrm{RIA}$ & & $\mathrm{p}=0.02$ vs. RIA \\
\hline RUNX2 & & & & $\mathrm{p}=0.02$ vs. RIA \\
\hline \multicolumn{5}{|l|}{ WNT3A } \\
\hline LRP5 & & & & $\mathrm{p}=0.03$ vs. RIA \\
\hline \multicolumn{5}{|l|}{ DKK1 } \\
\hline \multicolumn{5}{|l|}{ CTNNB1 } \\
\hline BGLAP & & $\mathrm{p}=0.02$ vs. RIA & $\mathrm{p}=0.04 \mathrm{vs} . \mathrm{RIA}$ & $\mathrm{p}=0.002 \mathrm{vs} . \mathrm{RIA}$ \\
\hline \multicolumn{5}{|l|}{ COL1A } \\
\hline ALPL & & & & \\
\hline
\end{tabular}

C, Comparison between control conditions (cont) and osteogenic-inducing conditions (ost. diff)

\begin{tabular}{|c|c|c|c|c|}
\hline Gene & $\begin{array}{c}\text { Femur (RIA) } \\
\text { cont. vs. ost. diff. }\end{array}$ & $\begin{array}{l}\text { Femur (spoon) } \\
\text { cont. vs. ost. diff. }\end{array}$ & $\begin{array}{l}\text { Iliac crest (spoon) } \\
\text { cont. vs. ost. diff. }\end{array}$ & $\begin{array}{l}\text { Iliac crest (asp.) } \\
\text { cont. vs. ost. diff. }\end{array}$ \\
\hline BMP2 & 0.21 , n.s. & 0.46, n.s. & 0.71, n.s. & 0.66, n.s. \\
\hline SMAD5 & 0.48, n.s. & 0.81, n.s. & 0.83, n.s. & 0.46, n.s. \\
\hline RUNX2 & 0.91, n.s. & 0.91, n.s. & 0.36 , n.s. & 0.83, n.s. \\
\hline WNT3A & 0.73 , n.s. & 0.51, n.s. & 0.20 , n.s. & 0.02, significant \\
\hline LRP5 & 0.43 , n.s. & 0.77 , n.s. & 0.58 , n.s. & 0.43, n.s. \\
\hline DKK1 & 0.53, n.s. & 0.75, n.s. & 0.11 , n.s. & 0.19, n.s. \\
\hline CTNNB1 & 0.68, n.s. & 0.24, n.s. & 0.81, n.s. & 0.13 , n.s. \\
\hline BGLAP & 0.47, n.s. & 0.34, n.s. & 0.22, n.s. & 0.24 , n.s. \\
\hline COL1A & 0.26 , n.s. & 0.91, n.s. & 0.85 , n.s. & 0.12, n.s. \\
\hline ALPL & 0.51 , n.s. & 0.65 , n.s. & 0.16 , n.s. & 0.41, n.s. \\
\hline
\end{tabular}

aOnly p-values $<0.05$ are presented in (A and B). The statistical evaluation of the comparison between MSCs cultivated under control and osteogenic-inducing conditions is shown in (C). Most differences found under osteogenic differentiation conditions were not significant with the exception of WNT3A gene expression in MSCs harvested from the iliac crest. n.s., no significance. RIA, Reamer/Irrigator/Aspirator; spoon, obtained using a spoon; asp., obtained by fine-needle aspiration. 



Figure 3. Expression of genes involved in BMP-2 signaling depending on the tissue site and harvest procedure of mesenchymal stem cells (MSCs) under control and osteogenic-inducing conditions (OD). Gene expression of (A) BMP2, (B) RUNX2 and (C) SMAD5 was normalized to GAPDH gene expression by the $\Delta \mathrm{Ct}$ method. Values are presented as boxplots of the median. MSCs obtained from the femur by RIA (F-RIA), from the femur using a spoon (F-Spo), from the iliac crest using a spoon (IC-Spo) and from the iliac crest by fine-needle aspiration (IC-Asp) were analyzed. "p $<0.05$. Exact p-values are additionally shown in Table I. RIA, Reamer/Irrigator/Aspirator.

derived MSCs (by fine-needle aspiration) in comparison with the femur-derived MSCs (by RIA). No significant differences were observed between the MSCs obtained from the iliac crest (using a spoon) and those obtained from the femur (using a spoon) (Fig. 4 and Table I).

Heterogeneous gene methylation. We analyzed the percentage of intermediate methylated and hypermethylated DNA sequences from the broad selection of our target genes in the MSCs at the 1st culture passage. The analysis revealed a hetero-

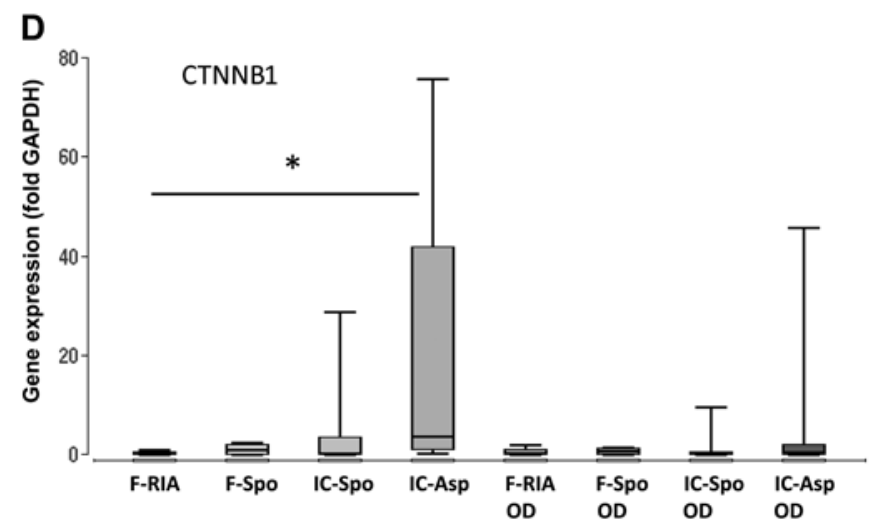

Figure 4. Expression of genes involved in WNT signaling depending on the tissue site and harvest procedure of mesenchymal stem cells (MSCs) under control and osteogenic-inducing conditions (OD). Gene expression of (A) WNT3A, (B) LRP5, (C) DKK1 and (D) CTNNB1 was normalized to GAPDH gene expression by the $\Delta \mathrm{Ct}$ method. Values are presented as boxplots of the median. MSCs obtained from the femur by RIA (F-RIA), from the femur using a spoon (F-Spo), from the iliac crest using a spoon (IC-Spo) and from the iliac crest by fine needle aspiration (IC-Asp) were analyzed. * $p<0.05$. Exact p-values are additionally shown in Table I. RIA, Reamer/Irrigator/Aspirator. 
Table II. Degree of intermediate DNA methylation (\%) in mesenchymal stem cells (MSCs) obtained from either the iliac crest or the femur using different harvest techniques. ${ }^{\mathrm{a}}$

A, Gene methylation

\begin{tabular}{|c|c|c|c|c|}
\hline Gene & Femur (RIA) & Femur (spoon) & Iliac crest (spoon) & Iliac crest (aspirates) \\
\hline \multirow[t]{3}{*}{ COL1A } & M: 0.0 & M: 0.0 & M: 25.0 & M: 0.0 \\
\hline & LQ: 0.0 & LQ: 0.0 & LQ: 0.0 & LQ: 0.0 \\
\hline & UQ: 30.1 & UQ: 17.6 & UQ: 34.1 & UQ: 01 \\
\hline \multirow[t]{3}{*}{ CTNNB1 } & M: 0.0 & M: 5.5 & M: 9.6 & M: 5.3 \\
\hline & LQ: 0.0 & LQ: 0.0 & LQ: 0.0 & LQ: 0.0 \\
\hline & UQ: 80.5 & UQ: 77.7 & UQ: 38.2 & UQ: 14.9 \\
\hline \multirow[t]{3}{*}{ RUNX2 } & M: 11.4 & M: 40.6 & M: 0.0 & M: 0.0 \\
\hline & LQ: 0.0 & LQ: 0.0 & LQ: 0.0 & LQ: 0.0 \\
\hline & UQ: 40.3 & UQ: 99.8 & UQ: 6.6 & UQ: 2.6 \\
\hline \multirow[t]{3}{*}{ SMAD5 } & M: 6.5 & M: 48.6 & M: 82.6 & M: 1.6 \\
\hline & LQ: 0.0 & LQ: 0.0 & LQ: 31.3 & LQ: 0.0 \\
\hline & UQ: 100.0 & UQ: 100.0 & UQ: 100.0 & UQ: 43.5 \\
\hline \multirow[t]{3}{*}{ WNT3A } & M: 0.0 & M: 0.0 & $\mathrm{M}: 0.0$ & M: 8.6 \\
\hline & LQ: 0.0 & LQ: 0.0 & LQ: 0.0 & LQ: 0.0 \\
\hline & UQ: 0.0 & UQ: 54.4 & UQ: 0.0 & UQ: 11.7 \\
\hline
\end{tabular}

B, Statistical evaluation (intergroup comparison between different MSC sources)

\begin{tabular}{llll}
\hline Gene & Femur (RIA) & Femur (spoon) & Iliac crest (spoon)
\end{tabular}

COL1A

CTNNB1

RUNX2 $\quad \mathrm{p}(\mathrm{nc})=0.08$ vs. aspirates

$\mathrm{p}(\mathrm{nc})=0.05$ vs. aspirates

$\mathrm{p}(\mathrm{nc})=0.08$ vs. iliac

crest (spoon)

SMAD5

$\mathrm{p}=0.05$ (nc) vs. aspirates

WNT3A

$\mathrm{p}(\mathrm{nc})=0.05$ vs. RIA

${ }^{\mathrm{a}}$ Gene methylation was measured by a PCR-based assay as indicated in the Materials and methods. Values are presented as median (M), 25\% quartile (LQ) and 75\% quartile (UQ) (A). Statistical evaluation (intergroup comparison between different MSC sources) is shown in (B). $\mathrm{p}(\mathrm{nc})$ indicate non-corrected (nc) local p-values without Bonferroni-Holm correction for multiple comparisons. Not corrected statistical significance can be interpreted as a statistical trend. RIA, Reamer/Irrigator/Aspirator; spoon, obtained using a spoon; aspirates, obtained by fine-needle aspiration

geneous methylation of osteogenic genes between the groups. The iliac crest-derived MSCs (by fine-needle aspiration) exhibited a decreased methylation of the RUNX2 gene in comparison with the femur-derived MSCs (using the RIA technique and using a spoon) and a decreased methylation of the SMAD5 gene in comparison with the iliac crest-derived MSCs (using a spoon). The WNT3A gene in the iliac crest-derived MSCs (by fine-neelde aspiration) exhibited an increased methylation in comparison with the femur-derived MSCs (by RIA) (Table II). No correlation was observed between the gene methylation and gene expression of the respective genes in either the control MSCs or in the osteogenically differentiated MSCs (data not shown).
The percentage of hypermethylated DNA sequences was generally lower compared with some intermediate methylation. A significantly increased hypermethylation of the COL1A gene was observed in the MSCs obtained from the femur (using the RIA technique and using a spoon), as well as in the MSCs from the iliac crest (using a spoon) in comparison with the MSCs obtained from the iliac crest by fine-needle aspiration. The increased hypermethylation of the WNT3A gene was observed in the MSCs obtained from the femur by RIA in comparison with the MSCs obtained from the iliac crest by fine-needle aspiration (Table III).

Negative correlations between the degree of RUNX2 hypermethylation and the gene expression of the RUNX2-regulated 
Table III. Percentage of hypermethylated DNA (\%) in mesenchymal stem cells (MSCs) obtained either from the iliac crest or from the femur using different harvest techniques. ${ }^{\text {a }}$

\begin{tabular}{lllll} 
A, Gene methylation & \multicolumn{5}{c}{} & \\
\hline Gene & Femur (RIA) & Femur (spoon) & Iliac crest (spoon) & Iliac crest (aspirate) \\
\hline COL1A & M: 0.6 & M: 1.0 & M: 2.0 & M: 0.1 \\
& LQ: 0.5 & LQ: 0.7 & LQ: 0.6 & LQ: 0.1 \\
& UQ: 2.5 & UQ: 8.5 & UQ: 2.9 & UQ: 0.7 \\
CTNNB1 & M: 0.2 & M: 0.1 & M: 2.6 & M: 0.2 \\
& LQ: 0.0 & LQ: 0.0 & LQ: 0.9 & LQ: 0.1 \\
& UQ: 1.2 & UQ: 0.3 & UQ: 10.9 & UQ: 0.4 \\
RUNX2 & M: 2.1 & M: 1.8 & M: 4.3 & M: 0.6 \\
& LQ: 0.4 & LQ: 0.4 & LQ: 2.5 & LQ: 0.3 \\
& UQ: 30.4 & UQ: 14.0 & UQ: 19.5 & UQ: 2.2 \\
SMAD5 & M: 7.9 & M: 0.4 & M: 2.2 & M: 0.3 \\
& LQ: 0.0 & LQ: 0.0 & LQ: 0.0 & LQ: 0.2 \\
& UQ: 26.7 & UQ: 40.8 & UQ: 17.0 & UQ: 3.6 \\
WNT3A & M: 4.9 & M: 1.7 & M: 2.4 & M: 0.4 \\
& LQ: 1.1 & LQ: 0.1 & LQ: 0.2 & LQ: 0.2 \\
& UQ: 82.7 & UQ: 25.3 & UQ: 5.4 & UQ: 0.5 \\
\hline
\end{tabular}

B, Statistical evaluation (intergroup comparison between MSCs obtained from different sources)

\begin{tabular}{lllll}
\hline Gene & Femur (RIA) & Femur (spoon) & Iliac crest (spoon) & Iliac crest (aspirates) \\
\hline COL1A & $\begin{array}{l}\mathrm{p}=0.1 \text { vs. iliac } \\
\text { crest aspirates }\end{array}$ & $\begin{array}{l}\mathrm{p}=0.05 \text { vs. iliac } \\
\text { crest aspirates }\end{array}$ & $\begin{array}{l}\mathrm{p}=0.05 \text { vs. iliac } \\
\text { crest aspirates }\end{array}$
\end{tabular}

CTNNB1

RUNX2

$\mathrm{p}=0.08$ vs. iliac

crest aspirates

SMAD5

WNT3A $\quad \mathrm{p}=0.04$ vs. iliac

crest aspirates

${ }^{\mathrm{a}}$ Gene methylation was measured by a PCR-based assay as indicated in the Materials and methods. Values are presented as median (M), 25\% quartile (LQ) and 75\% quartile (UQ) (A). Statistical evaluation (intergroup comparison between different MSC sources) is shown in (B). p(nc) indicate non-corrected (nc) local p-values without Bonferroni-Holm correction for multiple comparisons. Not corrected statistical significance may be interpreted as a statistical trend. RIA, Reamer/Irrigator/Aspirator; spoon, obtained using a spoon; aspirates, obtained by fine-needle aspiration.

genes, LRP5 (rho $=-0.42, \mathrm{p}=0.03)$, collagen $-1 \alpha($ rho $=-0.37$, $\mathrm{p}=0.04$ ) and smad5 (rho $=-0.36, \mathrm{p}=0.05$ ) were recorded. The expression of the RUNX2 gene correlated in trend with the hypermethylation of the RUNX2 gene (rho $=-0.29, \mathrm{p}=0.13$ ) whereas no correlations were observed between RUNX2independent gene expression (WNT3A, CTNNB1, DKK) and RUNX2 gene hypermethylation.

Significant decrease in the osteogenic differentiation capacity with increasing passage number. The calcium deposition capacity and gene expression were also assessed at the 3rd and 6th MSC culture passage, respectively except in the MSCs obtained from the iliac crest (by fine-needle aspiration), which were only assessed at the 1st passage (calcium deposition) and 3rd passage (gene expression). Higher passage numbers led to a marked decrease in the capacity of MSCs for osteogenic differentiation. Calcium deposition decreased significantly from the 1st to the 3rd passage. MSCs at the 6th passage demonstrated the lowest values. A decline in calcium deposition was observed in all the MSC cultures regardless of the source and isolation procedure (Fig. 5).

The expression of all analyzed genes decreased significantly in all the groups from the 1st to the 6th culture passage, except for the iliac crest aspirate-derived MSCs which were analyzed only up to the 3rd passage and no significant differences were observed between the $3 \mathrm{rd}$ and 6 th passage. Osteogenic 
A von Kossa staining, MSC obtained with RIA

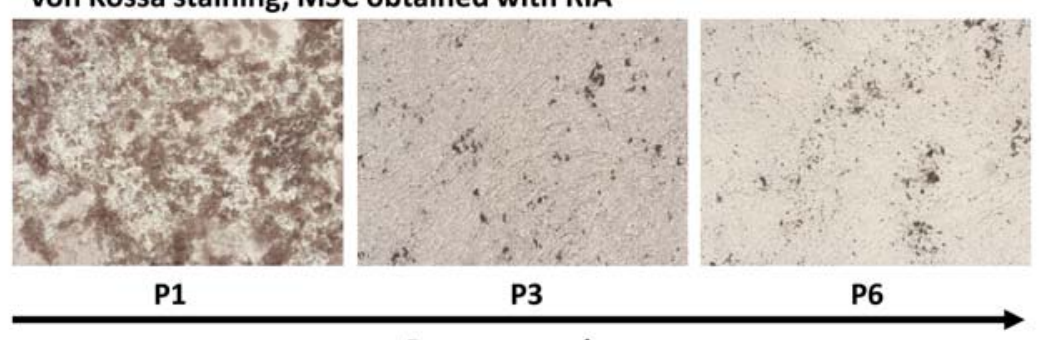

Passage number

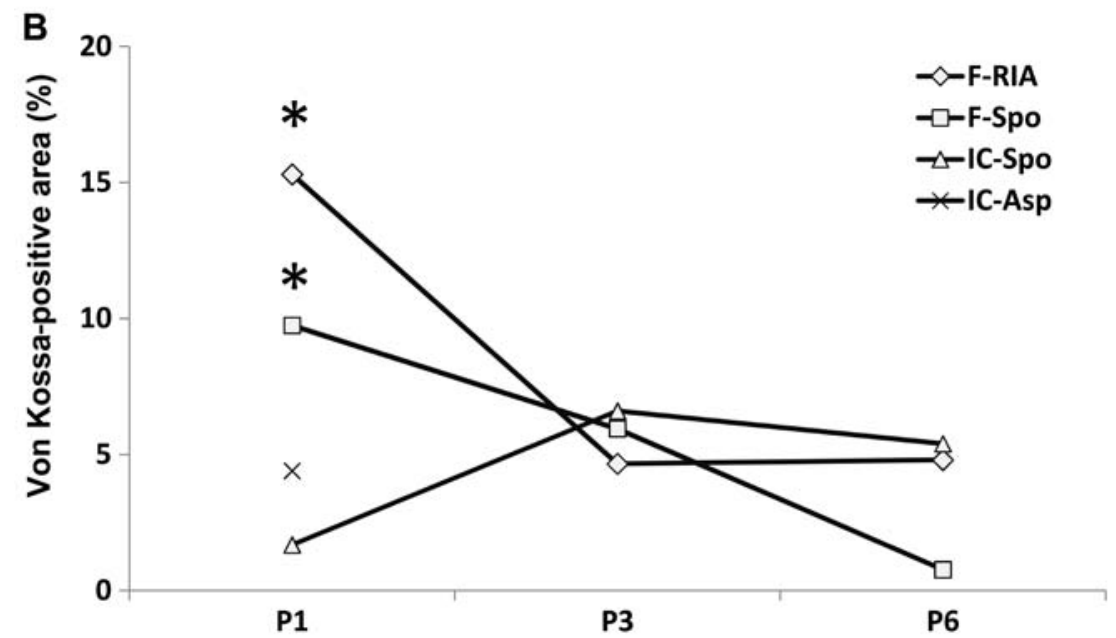

Figure 5. Decline in calcium deposition with the increasing passage number of mesenchymal stem cells (MSCs). (A) Representative images of von Kossa staining of osteogenically differentiated MSCs of passage 1, 3 and 6 are shown (original magnification x50). (B) Evaluation of the von Kossa staining. A significant decline in the von Kossa-positive areas was noted between MSCs of the 1st and MSCs of the 6th culture passages. MSCs were obtained from the femur using the Reamer/ Irrigator/Aspirator (RIA) technique (diamond), from the femur using a spoon (square), from the iliac crest using a spoon (triangle) or from the iliac crest by fineneedle aspiratoin (x). Only data of the 1st culture passage were available for the MSCs obtained from the iliac crest. "p $<0.05$ culture passage 1 vs. culture passage 6 .

stimulation over 14 days did not enhance the gene expression of the analyzed genes in comparison with that in the untreated controls; however, the decrease in gene expression with the increasing passage number was partially less pronounced for BMP2 (femur spoon, iliac crest spoon), DKK1 (femur spoon, iliac crest spoon), BGLAP(RIA, femur spoon, iliac crest spoon), COL1A (RIA) and ALPL (femur spoon, iliac crest spoon) when compared with their respective controls (Table IV).

\section{Discussion}

Previously, we observed that the MSCs obtained from the femur had a greater potential for osteogenic differentiation in comparison with the MSCs obtained from the iliac crest using the fine-needle aspiration technique (7). In order to conduct the experiments, the MSCs had to be expanded from a few hundred to at least $1 \times 10^{5}$ cells. The inheritance of the improved osteogenic capacity over several cell divisions suggests that osteogenic pathways undergo long-lasting alterations in the femur-derived MSCs. Thus, we hypothesized that these differences were due to the activation processes mediated by the different harvest procedures or the different environmental mechanical load of the MSCs at their respective body site. The latter may lead to a prevalence of osteogenic signaling pathways in the MSCs obtained from the femur due to the distinct methylation pattern of osteogenic genes.
Hence, the present study was conducted to examine the effects of the tissue site and the harvest procedure on the osteogenic functions and the gene regulation of osteogenic pathways in human MSCs. We were able to demonstrate that functional aspects (calcium deposition) and gene expression in MSCs were more affected by the harvest technique than the tissue site. However, the diminishing differences were observed after 6 culture passages and no significant evidence was found that differential methylation patterns of osteogenic genes play an important role in the functional alterations of the MSCs.

Influence of the harvest technique and mechanical strain on osteogenic differentiation. The MSCs obtained from the femor demonstrated an increased mean calcium deposition activity in comparison with the MSCs obtained from the iliac crest. This difference was significant for the MSCs obtained using the RIA technique. This finding is in line with previously published results from our group comparing the osteogenic differentiation capabilities of the MSCs obtained from the iliac crest by fine-needle aspiration with those isolated from the human femur (7), and also MSCs obtained from porcine femurs by RIA, as shown by another group (10). Contrary results were reported by Sanchez-Guijo et al (11). They reported the slightly, but not significantly increased osteogenic differentiation of MSCs obtained from the femoral head 
Table IV. Impairment of gene expression with the increasing passage number. ${ }^{\mathrm{a}}$

A, Control conditions

\begin{tabular}{|c|c|c|c|c|c|c|c|c|c|c|}
\hline Harvest sites & BGLAP & COL1A & ALP & BMP2 & RUNX2 & SMAD5 & WNT3A & LRP5 & DKK1 & CTNNB1 \\
\hline \multicolumn{11}{|l|}{ Femur, RIA } \\
\hline Pas. 1 & 100 & 100 & 100 & 100 & 100 & 100 & 100 & 100 & 100 & 100 \\
\hline Pas. 3 & $53 \pm 31$ & $106 \pm 35$ & $8 \pm 4$ & $52 \pm 38$ & $289 \pm 134$ & $15 \pm 7$ & $0 \pm 0$ & $4 \pm 2$ & $17 \pm 13$ & $16 \pm 3$ \\
\hline Pas. 6 & $16 \pm 7^{b}$ & $10 \pm 3^{b}$ & $10 \pm 6^{\mathrm{b}}$ & $2 \pm 1^{b}$ & $9 \pm 4^{\mathrm{b}}$ & $3 \pm 2^{b}$ & $0 \pm 0^{\mathrm{b}}$ & $0 \pm 0^{\mathrm{b}}$ & $3 \pm 2^{b}$ & $1 \pm 0^{\mathrm{b}}$ \\
\hline \multicolumn{11}{|l|}{ Femur, spoon } \\
\hline Pas. 1 & 100 & 100 & 100 & 100 & 100 & 100 & 100 & 100 & 100 & 100 \\
\hline Pas. 3 & $13 \pm 5$ & $16 \pm 8$ & $9 \pm 5$ & $16 \pm 5$ & $37 \pm 15$ & $5 \pm 2$ & $0 \pm 0$ & $0 \pm 0$ & $0 \pm 0$ & $11 \pm 3$ \\
\hline Pas. 6 & $18 \pm 17^{b}$ & $5 \pm 1^{b}$ & $5 \pm 5^{b}$ & $53 \pm 51^{b}$ & $5 \pm 4^{b}$ & $3 \pm 3^{b}$ & $0 \pm 0^{\mathrm{b}}$ & $12 \pm 12^{b}$ & $1 \pm 1^{b}$ & $5 \pm 5^{b}$ \\
\hline \multicolumn{11}{|l|}{ Il. cre. spoon } \\
\hline Pas. 1 & 100 & 100 & 100 & 100 & 100 & 100 & 100 & 100 & 100 & 100 \\
\hline Pas. 3 & $19 \pm 5$ & $4 \pm 1$ & $11 \pm 6$ & $14 \pm 5$ & $39 \pm 11$ & $0 \pm 0$ & $0 \pm 0$ & $0 \pm 0$ & $15 \pm 14$ & $7 \pm 3$ \\
\hline Pas. 6 & $12 \pm 5^{\mathrm{b}}$ & $6 \pm 3^{b}$ & $31 \pm 16^{\mathrm{b}}$ & $5 \pm 2^{b}$ & $38 \pm 16^{\mathrm{b}}$ & $1 \pm 1^{b}$ & $13 \pm 11^{\mathrm{b}}$ & $1 \pm 0^{\mathrm{b}}$ & $10 \pm 7^{b}$ & $2 \pm 1^{b}$ \\
\hline \multicolumn{11}{|l|}{ Il. cre. asp. } \\
\hline Pas. 1 & 100 & 100 & 100 & 100 & 100 & 100 & 100 & 100 & 100 & 100 \\
\hline Pas. 3 & $0 \pm 0^{\mathrm{b}}$ & $1 \pm 1^{\mathrm{b}}$ & $0 \pm 0^{\mathrm{b}}$ & $0 \pm 0^{\mathrm{b}}$ & $0 \pm 0^{\mathrm{b}}$ & $0 \pm 0^{\mathrm{b}}$ & $0 \pm 0^{\mathrm{b}}$ & $0 \pm 0^{\mathrm{b}}$ & $0 \pm 0^{\mathrm{b}}$ & $1 \pm 1^{b}$ \\
\hline
\end{tabular}

B, Osteogenic-inducing conditions

\begin{tabular}{|c|c|c|c|c|c|c|c|c|c|c|}
\hline Harvest sites & BGLAP & COL1A & ALP & BMP2 & RUNX2 & SMAD5 & WNT3A & LRP5 & DKK1 & CTNNB1 \\
\hline \multicolumn{11}{|l|}{ Femur, RIA } \\
\hline Pas. 1 & 100 & 100 & 100 & 100 & 100 & 100 & 100 & 100 & 100 & 100 \\
\hline Pas. 3 & $2 \pm 3$ & $112 \pm 21$ & $17 \pm 12$ & $24 \pm 22$ & $11 \pm 3$ & $0 \pm 0$ & $0 \pm 0$ & $1 \pm 1$ & $1 \pm 1$ & $2 \pm 1$ \\
\hline Pas. 6 & $28 \pm 23$ & $107 \pm 96$ & $6 \pm 5^{b}$ & $1 \pm 1^{b}$ & $5 \pm 3^{b}$ & $0 \pm 0^{\mathrm{b}}$ & $0 \pm 0^{\mathrm{b}}$ & $0 \pm 0^{\mathrm{b}}$ & $0 \pm 0^{\mathrm{b}}$ & $0 \pm 0^{\mathrm{b}}$ \\
\hline \multicolumn{11}{|l|}{ Femur, spoon } \\
\hline Pas. 1 & 100 & 100 & 100 & 100 & 100 & 100 & 100 & 100 & 100 & 100 \\
\hline Pas. 3 & $62 \pm 49$ & $24 \pm 17$ & $160 \pm 113$ & $13 \pm 9$ & $31 \pm 21$ & $0 \pm 0$ & $0 \pm 0$ & $61 \pm 12$ & $56 \pm 56$ & $61 \pm 32$ \\
\hline Pas. 6 & $32 \pm 30$ & $10 \pm 2^{b}$ & $47 \pm 35$ & $49 \pm 48$ & $23 \pm 6$ & $7 \pm 7^{\mathrm{b}}$ & $8 \pm 8^{b}$ & $0 \pm 0^{\mathrm{b}}$ & $33 \pm 33$ & $1 \pm 1^{b}$ \\
\hline \multicolumn{11}{|l|}{ Il. cre. spoon } \\
\hline Pas. 1 & 100 & 100 & 100 & 100 & 100 & 100 & 100 & 100 & 100 & 100 \\
\hline Pas. 3 & $992 \pm 910$ & $28 \pm 21$ & $14 \pm 8$ & $613 \pm 552$ & $13 \pm 4$ & $1 \pm 0$ & $0 \pm 0$ & $1 \pm 1$ & $1 \pm 1$ & $9 \pm 3$ \\
\hline Pas. 6 & $117 \pm 49$ & $7 \pm 4^{\mathrm{b}}$ & $22 \pm 15$ & $32 \pm 16$ & $16 \pm 10$ & $282 \pm 274$ & $8 \pm 3^{b}$ & $0 \pm 0^{\mathrm{b}}$ & $36 \pm 15$ & $14 \pm 14^{b}$ \\
\hline \multicolumn{11}{|l|}{ Il. cre. asp. } \\
\hline Pas. 1 & 100 & 100 & 100 & 100 & 100 & 100 & 100 & 100 & 100 & 100 \\
\hline Pas. 3 & $3 \pm 4^{b}$ & $4 \pm 3^{b}$ & $3 \pm 3^{b}$ & $0 \pm 0^{\mathrm{b}}$ & $5 \pm 5^{\mathrm{b}}$ & $0 \pm 0^{\mathrm{b}}$ & $0 \pm 0^{\mathrm{b}}$ & $0 \pm 0^{\mathrm{b}}$ & $1 \pm 1^{\mathrm{b}}$ & $0 \pm 0^{\mathrm{b}}$ \\
\hline
\end{tabular}

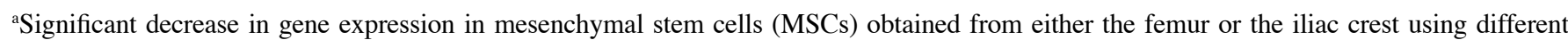
harvest techniques with the increasing passage number. Expression of genes in MSCs cultured under control conditions is presented in (A), expression of genes under osteogenic-inducing conditions is shown in (B). Data are normalized to gene expression level at passage $1(=100 \%)$. Data are presented as the mean values and standard error of mean (SEM). Gene expression at passage 6 (passage 3 for MSCs from iliac crest aspirates) was compared to gene expression at culture passage 1 for statistical evaluation. ${ }^{\mathrm{b}} \mathrm{p}<0.05$.

through a milling procedure compared with those obtained from the iliac crest aspirates. The milling procedure may not be comparable with the RIA process and thus, may explain the comparatively low difference between the femor-derived MSCs and the iliac crest-derived MSCs in terms of osteogenesis (11).
RIA technology was developed to avoid the disadvantages of conventional techniques used for intramedullary reaming, such as marked increases in intramedullary pressure with pressure peaks of up to $2.7 \times 10^{4} \mathrm{~Pa}$ to $2.0 \times 10^{5} \mathrm{~Pa}$ and temperatures at the reaming head up to $67^{\circ} \mathrm{C}(12)$. Using a porcine and a sheep model, respectively, Husebye et al and Pape et al observed that 
the application of RIA indeed led to a significant reduction of intramedullary pressure in the femur to almost baseline levels and to a significant decrease in systemic inflammation in comparison with conventional medullary nailing $(13,14)$. The reaming process itself is a harsh procedure, exerting high shear forces on the cells due to the continuous drilling and aspiration process. Many different cell types have been demonstrated to be highly mechanosensitive in vitro (15). As regards MSCs, it has been further described that tensile strain, shear stress and compressive loading support the osteogenic differentiation of MSCs and inhibit adipogenesis (16-18).

Another factor which contributes to the improved osteogenic differentiation of femor-derived MSCs compared to iliac crestderived MSCs may be the differential daily mechanical load of the bones from which the cells are isolated. The association between mechanical load and tissue formation has roots going back to to the work of Wolff (1892), who suggested that the daily mechanical environment influences the morphology of the skeletal tissue architecture. Previous research has confirmed this and suggests that this phenomenon plays a crucial role in creating, maintaining or repairing the skeleton $(19,20)$. The 'mechanosensitivity' of the skeleton is likely to exert a direct effect on the gene expression pattern, molecular architecture and tissue type during the process of development and healing (21). It is also feasible to assume that the high daily mechanical loading of the femur will lead to distinct methylation patterns of osteogenic genes in femor-derived MSCs in order to prime the cells for their putative development in regards to the osteoblastic lineage. Tissue site-specific differences in gene methylation were described for MSCs derived from the iliac crest in comparison with MSCs derived from adipose tissue. Non-adipogenic lineage-specific promoters are hypermethylated, raising the hypothesis that adipose-derived MSCs are epigenetically preprogrammed for adipogenesis (22).

Our gene expression analysis frequently revealed the reduced expression of BMP2 and the WNT family in the MSCs obtained using the RIA technique from the femur in comparison with MSCs obtained from the iliac crest by fine-needle aspiration, although it has been reported that the mechanical load induces the rapid expression of BMP-2, cbfa-1 and smad5, which further enhances the gene expression of ALP, collagen type 1, osteocalcin and osteopontin (23). Furthermore, more recent research suggests that pathways such as the $\mathrm{Wnt} / \beta$-catenin signaling pathway are also triggered by mechanical stimuli. The prevention of the adipogenic differentiation and the improvement of the osteogenic differentiation of MSCs through mechanical loading is due to the activation of $\beta$-catenin (24).

Of note, we observed the reduced expression of osteogenic genes in the MSCs isolated using the RIA technique, the cells that putatively received the highest mechanical stimuli in the present study. However, this finding does not necessarily imply the denial of the hypothesis that the mechanical stimulation of MSCs supports osteogenic differentiation for the following reasons. An important factor is the time that passes between the isolation of the cells and the measurements. Whereas other researchers stimulated cultured MSCs in vitro and directly measured gene expression or cell functions $(15,25,26)$, the MSCs used in our study received mechanical stimuli a long time prior to the measurement, while residing in their respective bone and during their subsequent harvest procedure. Furthermore, a review of the literature revealed that the duration of the stimulus and the type of stimulus are critical factors for the induction of osteogenesis. For example, it has been demonstrated that a $10 \%$ global strain of human bone marrow-derived MSCs led to tenogenesis, whereas a ' $3 \%$ strain favoured osteogenic differentiation' (15).

Compression loading, on the other hand, seems to support the formation of mineralized bone-like matrix (25). One might argue that the compression load is a major force affecting MSCs residing in the femur. This may explain the improved calcium deposition that was noted for the femor-derived MSCs in comparison with the MSCs obtained from the iliac crest. The higher calcium deposition in the femor-derived MSCs isolated using the RIA technique may be due to further stimulation mediated by additional shear stress, which is supposed to enhance osteogenesis, as summarized by McCoy and O'Brien (26). Moreover, it is also conceivable that molecular danger signals released from necrotic cells during the reaming procedure stimulate the osteogenic activity of MSCs. Evidence has indicated that mechanical, as well as alarmin-induced stimulation leads to the activation of mitogen-activated protein (MAP) kinases and that the activation of MAP kinases supports the process of osteogenesis (reviewed in ref. 27;28). Furthermore, it has been described that alarmins, such as high mobility group box 1 (HMGB1), support the osteogenic differentiation of MSCs (29). Hence, it may be assumed that the further increase in calcium deposition in MSCs isolated using the RIA technique reflects the combined stimulation with mechanical and molecular stimuli (by different types of alarmins).

The long-lasting changes in MSC functions in relation to the tissue site and the isolation procedure also suggest a role of the epigenetic pre-programming of major osteogenic pathways. DNA methylation is the most well-characterized epigenetic modification. CpG dinucleotides in mammalian genomic DNA may be methylated at cytosine moieties. Hypermethylation results in the repression of gene expression, whereas hypomethylation enables the transcription of certain genes. Upon replication, the same methylation pattern is established on the newly synthesized DNA strand by DNA methyltransferase-1, thus the methylation pattern is inherited by both daughter cells. Thus, the effects mediated by the alteration of gene methylation patterns may be effective over several cell generations (8). Methylation may affect gene transcription by directly interfering with transcription factors or methyl-CpG-binding proteins that modify histones and thereby inactivate the respective promoter region (30). Studies have demonstrated that epigenetic alterations are associated with the level of differentiation potential in human stem cells $(22,31)$. With regard to MSCs, it was recently demonstrated that 'DNA methylation restricts the spontaneous multi-lineage differentiation of mesenchymal progenitor cells, but is stable during growth factor-induced terminal differentiation' (31).

We observed trends towards the increased methylation of the RUNX2 gene, and the decreased methylation of the SMAD5 and WNT3A genes in the MSCs obtained using the RIA technique in comparison with the MSCs obtained from the iliac crest either by using a spoon or by fine-needle aspiration. The findings suggest that gene methylation may be altered, 
depending on the mechanical stress associated with the respective isolation method. This suggestion is supported by results published in the study by Arnsdorf et al (32); the methylation of the osteopontin gene decreased by $35 \%$ with exposure to oscillatory flow, whereas the methylation of the collagen I and osteocalcin genes remained unaltered (32). Based on our results, we cannot rule out that the tissue site may influence DNA methylation as well. For example, evidence suggests that MSCs derived from adipose tissue display an altered epigenetic pattern in comparison with the MSCs derived from the iliac crest. Non-adipogenic lineage-specific promoters are hypermethylated, raising the hypothesis that adipose-derived MSCs are epigenetically pre-programmed for adipogenesis (22).

Certainly, we could not calculate any correlation between the methylation/hypermethylation and the expression of the respective genes with the exception of the RUNX2 gene. The lack of correlations are not in conflict with current research. Evidence suggests that gene expression does not necessarily correlate with gene methylation. For example, van Eijk et al analyzed the DNA methylation and gene expression levels in the whole blood of 148 healthy human volunteers and reported ' 522 negative associations and 276 positive associations between methylation and expression levels' (33). As already mentioned, we observed that particularly the degree of hypermethylation of the RUNX-2 gene inversely correlated with the gene expression of the RUNX2-regulated genes, COL1A, LRP5, SMAD5, and in trend with RUNX2. This indicates that even slight percentages of hypermethylation of the RUNX2 gene may affect RUNX2 expression and thus, the expression of the RUNX-2 regulated genes. Conversly, Uehara et al reported that the hypermethylation of RUNX2 may be involved in the the lipopolysaccharide (LPS)induced inhibition of osteoblastic cell differentiation (34). These results underline the importance of RUNX2 for osteogenesis (35).

Surprisingly, we did not observe a relevant increase in the levels of typical osteogenic genes after 14 days of incubation in osteogenic differentiation medium. However, the gain of calcium deposition following osteogenic stimulation indicated that osteogenic processes had occurred. The kinetics of osteogenic gene expression have been extensively analyzed by Kulterer et al. The authors observed that the gene expression of ALPL and BMP2 peaked around day 4 and the gene expression of COL1A on day 7. BGLAP as a marker of matrix mineralization was 'maximally expressed on day 21'. Their 'results show that MSCs on day 7 of their differentiation were most similar to osteoblasts' (36). Hence, with regard to the present study, it appears most likely that the maximum expression levels of the analyzed genes had already passed by day 14 , and thus they did not reach peak levels on day 14 .

Effect of cell age on osteogenic differentiation. We observed a marked decrease in osteogenic differentiation with the increasing passage number, independently of the source of MSCs, as measured by means of calcium deposition and the expression of osteogenic genes. The cell age-dependent decline in the osteogenic capabilities of MSCs was first reported by Banfi et al (37). They observed that 'MSCs had a markedly diminished proliferation rate after the first passage and gradually lost their multiple differentiation potential' which was accompanied by a functional loss with regard to their bone formation capacity in vivo (37). Similar results were reported by Kretlow et al (38). They observed a significant decline in the calcium deposition capacity of MSCs from the first to the sixth culture passage (38). Reasons for the deprivation of osteogenic potential with the increasing passage number may be found in the loss of initial heterogenity of the adherent MSCs during ongoing cultivation due to the preferential proliferation of one over the other cell types as suggested by Kretlow et al (38). It is feasible to assume that the same effect is responsible for the decline in osteogenic differentiation independently of the harvest site and harvest procedure observed in the present study.

In conclusion, this observational study demonstrated that femor-derived MSCs isolated using the RIA technique exhibited a significantly improved calcium deposition. Furthermore, it was noted that calcium deposition, the expression of osteogenic genes and the gene methylation of the MSCs obtained from different tissue sites were similar to a great extent, when comparable tissue types were analyzed (cancellous bone) and comparable isolation procedures were applied (using a spoon). The latter results further suggest that the daily environmental mechanical load of the bone does not necessarily lead to significant alterations in the methylation and the expression of genes involved in osteogenesis in MSCs. Hence, the significantly altered gene expression and gene methylation of the MSCs harvested from the femur using the RIA technique may be attributed to the harsh isolation procedure. Our correlation analysis underlined the importance of the methylation state of the central osteogenic transcription factor, RUNX2, and the expression of RUNX2-regulated genes. However, the lack of correlation between the methylation and the expression of any other of the analyzed genes suggests that other cellular processes override the effects of gene methylation to a certain extent. In conclusion, we provide evidence herein that primarily, the harvest procedure and not the type of bone tissue determines the osteogenic capabilities of MSCs in vitro. Albeit, any differences in osteogenic capabilities were diminished with the increasing passage number. The variable differentiation ability of the MSCs, which depends on the harvest site and harvest technique, as well as the rapid loss of osteogenic differentiation capacity with the increasing culture time should be taken into consideration when using MSCs as a potential therapeutic application for bone tissue engineering.

\section{Acknowledgements}

This study was founded by the AORF: S-10-47-H.

\section{References}

1. Hannouche D, Petite H and Sedel L: Current trends in the enhancement of fracture healing. J Bone Joint Surg Br 83: 157-164, 2001.

2. Feinberg SE, Hollister SJ, Halloran JW, Gabe Chu TM and Krebsbach PH: A tissue engineering approach to site-specific reconstruction of skeletal structures of the maxillofacial region:part I. Shanghai Kou Qiang Yi Xue 9: 34-38, 2000 (In Chinese).

3. Feinberg SE, Hollister SJ, Halloran JW, Gabe Chu TM and Krebsbach PH: A tissue engineering approach to site specific reconstruction of skeletal structures of the maxillofacial region: part II. Shanghai Kou Qiang Yi Xue 9: 88-93, 2000 (In Chinese).

4. Petite H, Viateau V, Bensaïd W, Meunier A, de Pollak C, Bourguignon M, Oudina K, Sedel L and Guillemin G: Tissueengineered bone regeneration. Nat Biotechnol 18: 959-963, 2000. 
5. Schmidmaier G,Herrmann S, Green J, WeberT, Scharfenberger A, Haas NP and Wildemann B: Quantitative assessment of growth factors in reaming aspirate, iliac crest, and platelet preparation. Bone 39: 1156-1163, 2006.

6. Wenisch S, Trinkaus K, Hild A, Hose D, Herde K, Heiss C, Kilian O, Alt V and Schnettler R: Human reaming debris: a source of multipotent stem cells. Bone 36: 74-83, 2005.

7. Henrich D, Seebach C, Sterlepper E, Tauchmann C, Marzi I and Frank J: RIA reamings and hip aspirate: a comparative evaluation of osteoprogenitor and endothelial progenitor cells Injury 41 (Suppl 2): S62-S68, 2010.

8. Djupedal I and Ekwall K: Epigenetics: heterochromatin meets RNAi. Cell Res 19: 282-295, 2009.

9. Seebach C, Henrich D, Tewksbury R, Wilhelm K and Marzi I Number and proliferative capacity of human mesenchymal stem cells are modulated positively in multiple trauma patients and negatively in atrophic nonunions. Calcif Tissue Int 80: 294-300, 2007.

10. van der Bel R and Blokhuis TJ: Increased osteogenic capacity of Reamer/Irrigator/Aspirator-derived mesenchymal stem cells Injury 45: 2060-2064, 2014.

11. Sanchez-Guijo FM, Blanco JF, Cruz G, Muntion S, Gomez M, Carrancio S, Lopez-Villar O, Barbado MV, Sanchez-Abarca LI, Blanco B, et al: Multiparametric comparison of mesenchymal stromal cells obtained from trabecular bone by using a novel isolation method with those obtained by iliac crest aspiration from the same subjects. Cell Tissue Res 336: 501-507, 2009.

12. Henry SL, Adcock RA, Von Fraunhofer JA and Seligson D: Heat of intramedullary reaming. South Med J 80: 173-176, 1987.

13. Husebye EE, Lyberg T, Madsen JE, Eriksen M and Roise O: The influence of a one-step reamer-irrigator-aspirator technique on the intramedullary pressure in the pig femur. Injury 37: 935-940, 2006

14. Pape HC, Zelle BA, Hildebrand F, Giannoudis PV, Krettek C and van GM: Reamed femoral nailing in sheep: does irrigation and aspiration of intramedullary contents alter the systemic response? J Bone Joint Surg Am 87: 2515-2522, 2005.

15. Delaine-Smith RM and Reilly GC: Mesenchymal stem cell responses to mechanical stimuli. Muscles Ligaments Tendons J 2: 169-180, 2012.

16. Delaine-Smith RM and Reilly GC: The effects of mechanical loading on mesenchymal stem cell differentiation and matrix production. Vitam Horm 87: 417-480, 2011.

17. Sen B, Xie Z, Case N, Ma M, Rubin C and Rubin J: Mechanical strain inhibits adipogenesis in mesenchymal stem cells by stimulating a durable beta-catenin signal. Endocrinology 149: 6065-6075 2008.

18. Simmons CA, Matlis S, Thornton AJ, Chen S, Wang CY and Mooney DJ: Cyclic strain enhances matrix mineralization by adult human mesenchymal stem cells via the extracellular signalregulated kinase (ERK1/2) signaling pathway. J Biomech 36 : 1087-1096, 2003.

19. Beaupré GS, Stevens SS and Carter DR: Mechanobiology in the development, maintenance, and degeneration of articular cartilage. J Rehabil Res Dev 37: 145-151, 2000

20. Carter DR, Beaupré GS, Giori NJ and Helms JA: Mechanobiology of skeletal regeneration. Clin Orthop Relat Res (Suppl): S41-S55, 1998.

21. Cullinane DM, Salisbury KT, Alkhiary Y,Eisenberg S, Gerstenfeld L and Einhorn TA: Effects of the local mechanical environment on vertebrate tissue differentiation during repair: does repair recapitulate development? J Exp Biol 206: 2459-2471, 2003.

22. Boquest AC, Noer A and Collas P: Epigenetic programming of mesenchymal stem cells from human adipose tissue. Stem Cell Rev 2: 319-329, 2006
23. Rath B, Nam J, Knobloch TJ, Lannutti JJ and Agarwal S: Compressive forces induce osteogenic gene expression in calvarial osteoblasts. J Biomech 41: 1095-1103, 2008.

24. Sen B, Styner M, Xie Z, Case N, Rubin CT and Rubin J: Mechanical loading regulates NFATc1 and beta-catenin signaling through a GSK3beta control node. J Biol Chem 284 34607-34617, 2009.

25. Sittichokechaiwut A, Edwards JH, Scutt AM and Reilly GC: Short bouts of mechanical loading are as effective as dexamethasone at inducing matrix production by human bone marrow mesenchymal stem cell. Eur Cell Mater 20: 45-57, 2010.

26. McCoy RJ and O'Brien FJ: Influence of shear stress in perfusion bioreactor cultures for the development of three-dimensional bone tissue constructs: a review. Tissue Eng Part B Rev 16 587-601, 2010.

27. Thompson WR, Rubin CT and Rubin J: Mechanical regulation of signaling pathways in bone. Gene 503: 179-193, 2012.

28. Bianchi ME: DAMPs, PAMPs and alarmins: all we need to know about danger. J Leukoc Biol 81: 1-5, 2007.

29. Pistoia V and Raffaghello L: Damage-associated molecular patterns (DAMPs) and mesenchymal stem cells: a matter of attraction and excitement. Eur J Immunol 41: 1828-1831, 2011.

30. Jaenisch R and Bird A: Epigenetic regulation of gene expression: how the genome integrates intrinsic and environmental signals. Nat Genet 33 Suppl: 245-254, 2003.

31. Hupkes M, van Someren EP, Middelkamp SH, Piek E, van Zoelen EJ and Dechering KJ: DNA methylation restricts spontaneous multi-lineage differentiation of mesenchymal progenitor cells, but is stable during growth factor-induced terminal differentiation. Biochim Biophys Acta 1813: 839-849, 2011.

32. Arnsdorf EJ, Tummala P, Castillo AB, Zhang F and Jacobs CR: The epigenetic mechanism of mechanically induced osteogenic differentiation. J Biomech 43: 2881-2886, 2010.

33. van Eijk KR, de JS, Boks MP, Langeveld T, Colas F, Veldink JH, de Kovel CG, Janson E, Strengman E, Langfelder P, et al: Genetic analysis of DNA methylation and gene expression levels in whole blood of healthy human subjects. BMC Genomics 13: 636, 2012.

34. Uehara O, Abiko Y, Saitoh M, Miyakawa H and Nakazawa F: Lipopolysaccharide extracted from Porphyromonas gingivalis induces DNA hypermethylation of runt-related transcription factor 2 in human periodontal fibroblasts. J Microbiol Immunol Infect 47: 176-181, 2014.

35. Schroeder TM, Jensen ED and Westendorf JJ: Runx2: A master organizer of gene transcription in developing and maturing osteoblasts. Birth Defects Res C Embryo Today 75: 213-225, 2005.

36. Kulterer B, Friedl G, Jandrositz A, Sanchez-Cabo F, Prokesch A, Paar C, Scheideler M, Windhager R, Preisegger KH and Trajanoski Z: Gene expression profiling of human mesenchymal stem cells derived from bone marrow during expansion and osteoblast differentiation. BMC Genomics 8: 70, 2007.

37. Banfi A, Muraglia A, Dozin B, Mastrogiacomo M, Cancedda R and Quarto R: Proliferation kinetics and differentiation potential of ex vivo expanded human bone marrow stromal cells: implications for their use in cell therapy. Exp Hematol 28: 707-715, 2000.

38. Kretlow JD, Jin YQ, Liu W, Zhang WJ, Hong TH, Zhou G, Baggett LS, Mikos AG and Cao Y: Donor age and cell passage affects differentiation potential of murine bone marrow-derived stem cells. BMC Cell Biol 9: 60, 2008. 